\title{
Traditional Ecological Knowledge of Shifting Agriculture of Bulang People in Yunnan, China
}

\author{
Lun Yin ${ }^{1,2, *}$, Misiani Zachary ${ }^{3,5}$, Yanyan Zheng ${ }^{4}$, Xiaohan Zhang ${ }^{5}$, Antonine Sakwa ${ }^{6}$ \\ ${ }^{1}$ Center for Ecological Civilization, Southwest Forestry University, Kunming, China \\ ${ }^{2}$ Southwest Regional Ecological Civilization and Environmental Rule of Law Research Center, Leshan Normal University, Leshan, China \\ ${ }^{3}$ Kenya Meteorological Department, Ministry of Environment and Forestry, Nairobi, Kenya \\ ${ }^{4}$ Yunnan People's Publishing House Ltd, Kunming, China \\ ${ }^{5}$ Center for Biodiversity and Traditional Ecological Knowledge, Kunming, China \\ ${ }^{6}$ School of Environment, Water and Natural Resources, South Eastern Kenya University, Nairobi, Kenya \\ Email address: \\ 13888267735@163.com (Lun Yin), lun.yin@gmail.com (Lun Yin) \\ *Corresponding author
}

\section{To cite this article:}

Lun Yin, Misiani Zachary, Yanyan Zheng, Xiaohan Zhang, AntonineSakwa. Traditional Ecological Knowledge of Shifting Agriculture of Bulang People in Yunnan, China. American Journal of Environmental Protection. Vol. 9, No. 3, 2020, pp. 51-58.

doi: 10.11648/j.ajep.20200903.13

Received: May 3, 2020; Accepted: May 26, 2020; Published: June 8, 2020

\begin{abstract}
Land-use and land-cover changes directly impact biological diversity, and may cause land degradation by altering ecosystem services and livelihood support systems, thereby disrupting the socio-cultural practices and institutions associated with managing those biophysical systems. The most important is the gradual disappearance of human's traditional ecological knowledge and cultural diversity. Xishuangbanna is one of regions that have the richest biodiversity and cultural diversity in the world. In recent years, academic scholars, government departments at different levels and media have increasingly paid close attention on the relationship between rubber cultivation and biodiversity in Xishuangbanna. However, such attention on the relationship between rubber plantation and cultural diversity is few. Conclusively, social and cultural practice on natural resource management carried out by local people and relevant institutions are greatly changing in the context of implementing rubber plantation. During this process, traditional ecological knowledge is also experiencing changes. The paper will elaborate impacts from the rubber plantation on Bulang society in Xishuangbanna, explore changes on local subsistence, social and cultural practice and relevant institutions, and further analyze relationships between the rubber plantation, cultural diversity and traditional ecological knowledge, and threats and challenges faced by Bulang people. Through the case study of Bulang people, we see that the traditional ecological knowledge not only includes natural resource management and genetic resource protection, but also recognition of ethnical identities and heritage of biological and cultural diversity.
\end{abstract}

Keywords: Shifting Agriculture, Rubber Plantation, Traditional Ecological Knowledge, Agro-biodiversity, Xishuangbanna, Yunnan, China

\section{Introduction}

Along with population growth and economic development, people's requirements on natural resources are increasing, which directly affects the Earth's natural, geographical and biological systems. Changes on land utilization and vegetation are the most important factors affecting these systems. The most obvious case is that large areas of forest have been converted into farmland and grassland [3]. Changes in Land
Use Land Cover-LULC are among the most important human alterations affecting the surface of the earth [4]. Land-use and land-cover changes directly impact biological diversity [6], and may cause land degradation by altering ecosystem services and livelihood support systems, thereby disrupting the socio-cultural practices and institutions associated with managing those biophysical systems [7]. The most important is the gradual disappearance of human's Traditional Ecological Knowledge and cultural diversity. 
In recent years, biodiversity in Xishuangbanna is slowly vanishing. Now there are 109 endangered animals and 58 endangered plants classified as national protected species. The main reasons causing biodiversity disappearance are habitat loss, habitat destruction and change, exotic biological invasion, over-exploitation of natural resources, environmental pollution, global warming and industrialization of agriculture and forestry. Impacts from the industrialization of agriculture and forestry on biodiversity become more and more serious. For instance, the area of primary forest in Xishuangbanna greatly decreased in recent years, while the area of rubber trees increased year by year. In 1952, the area of primary forest in Xishuangbanna was 1.05 million hectares. Presently, the area is only 0.3 million hectares. People started to plant rubber trees in Xishuangbanna in 1950s. Till 1998 total area of rubber trees was 136,186 hectares [14]. Significant signs of changes in land utilization and vegetation were shown by conversion of tropical rain forest into rubber plantation [2].

Xishuangbanna is also one of areas rich in cultural diversity, inhabited by many ethnic minorities, such as Dai people who are living at basin area, and Hani, Jinuo, Yao, Lahu and Bulang people living in mountainous areas [9]. In those ethnic minorities' belief, they view some mountains as Sacred Mountain. Trees on these Sacred Mountains have been protected well by people until today [5]. Hani people believe in animism and ancestor worship. Trees nearby their ancestors cemeteries have been protected well. To-date, Hani people mainly depend on shifting agriculture for their subsistence. They will develop tea garden in tropical forest, excavate terraces, and raise livestock [10]. Bulang people believe in Buddhism and ancestor worship and as a result they protect the watershed forest strictly and well. At the same time, they developed a comprehensive agricultural system to reflect farming culture. This system well reflects their belief and how to manage forest, village and tea garden. Ethnic minorities of Xishuangbanna are rich in cultural diversity, which always has close relations to biodiversity and natural environment.

In recent years, academic scholars, government departments at different levels and media have increasingly paid close attention on the relationship between rubber cultivation and biodiversity in Xishuangbanna. However, such attention on the relationship between rubber plantation and cultural diversity is few. Conclusively, social and cultural practice on natural resource management carried out by local people and relevant institutions are greatly changing in the context of implementing rubber plantation. During this process, traditional ecological knowledge is also experiencing changes. The topic of the relationship between rubber cultivation, cultural diversity, and traditional ecological knowledge deserves interdisciplinary study by scholars from ecological anthropology, ethno-ecology and so on.

This article will select Manshan Village of Daluo Township of Menghai County of Xishuangbanna as a case study. The paper will elaborate impacts from the rubber plantation on local Bulang society, explore changes on local subsistence, social and cultural practice and relevant institutions, and further analyze relationships between the rubber plantation, cultural diversity and traditional ecological knowledge, and threats and challenges faced by Bulang people.

\section{Changes of Rubber Plantation on Xishuangbanna}

Since 1949, the state treated rubber as an important strategic resource. In order to provide rubber for national defense construction and deal with international blockade, the Chinese government made a formal decision on rubber cultivation in Xishuangbanna in 1951 [10]. In 1953 an investigation team was organized by botany experts from China and the former Soviet Union. They went to Xishuangbanna to do feasibility studies on rubber cultivation. In 1953 the Rubber Experimental Station and Ganlanba Farm were formally established. According to the experiment and rubber adaptability, in 1956 the Chinese government made decision to implement large-scale rubber plantation in Xishuangbanna and another southern region of Yunnan Province. From 1956 to 1982 there were 10 state-owned farms established, including 64 sub-farms [8]. As a result of an increase of the global rubber price in 2002, farmers in Xishuangbanna started to plant rubber even on shifting land. Farmers also rented shifting land from each other to plant rubber trees. Some workers from the state-owned farm started to rent land from villagers to plant rubber trees. At the same time, businessmen from other provinces also went to Xishuangbanna to rent land for the rubber plantation. Rubber cultivation already is a very important livelihood for 28 thousand farmers planting rubber trees and 15 thousand workers from the state-owned rubber farm. Rubber cultivation provides a rural per capita net income of 1056 yuan in Xishuangbanna, which is about $42.8 \%$ of total rural per capita net income in Xishuangbanna [12]. Rubber is an important cash crop planted by most farmers in Xishuangbanna.

Along with large scale plantation, however, negative impacts from the rubber plantation on the ecological environment become more and more serious. Area of tropical rainforest is decreasing. Water supply to some villages is also decreasing. Some people even call rubber trees "green desert", and treat it as main reason for the disappearance of tropical rainforest. Accordingly, local government's recognition on the rubber plantation is changing. In 2000, the Xishuangbanna prefectural government decided to restrict the rubber plantation area. In 2005 the prefectural government strictly required township governments not to expand the rubber plantation area.

The rubber plantation is directly related to governmental policy. In other words, rubber can be called a "policy plant". Local government's recognition on rubber experienced three stages from "strategic resource" and "economic plant/crop" to today's "ecological problem". It also can be shown by changes in the government's attitude towards rubber cultivation from previous encouragement and promotion to current restriction.

\section{Research Methodology and Area of Study}

\subsection{Research Methodology}

This article is based on interviews with local government 
and villagers and field work that was carried out between 2009 and 2011. Research methods include interdisciplinary analysis, policy and literature review, semi-structured interview, group discussion, questionnaire and observation.

The research site is Manshan Administrative Village of Daluo Township of Menghai County. Manshan Administrative Village (MAV) is located near the border between China and Burma. There are 11 villagers' groups under MAV administration, among which 9 are Bulang villages. According to different altitude and location, the authors chose Manshanshangzhai village and Manshanxiazhai village of Manshan Administrative Village for investigation. Manshanshangzhai village has 59 households with 261 people, and Manshanxiazhai village has 121 households with 559 people. In total, the authors carried out 20 semi-structured interviews and 5 group discussions. The interviewers and discussion groups were divided into three groups, namely a young group with age under 35, a middle-aged group aged 35 to 50 , and an older group with age above 50 . Relating to gender analysis, the interviewers and discussion group included 30 female villagers. Through age and gender analysis, we can understand villagers' response to rubber plantation quantitatively and qualitatively. We chose interviewers randomly. Additionally, we chose 25 households from two villages to do 50 questionnaires.

\subsection{Area of Study}

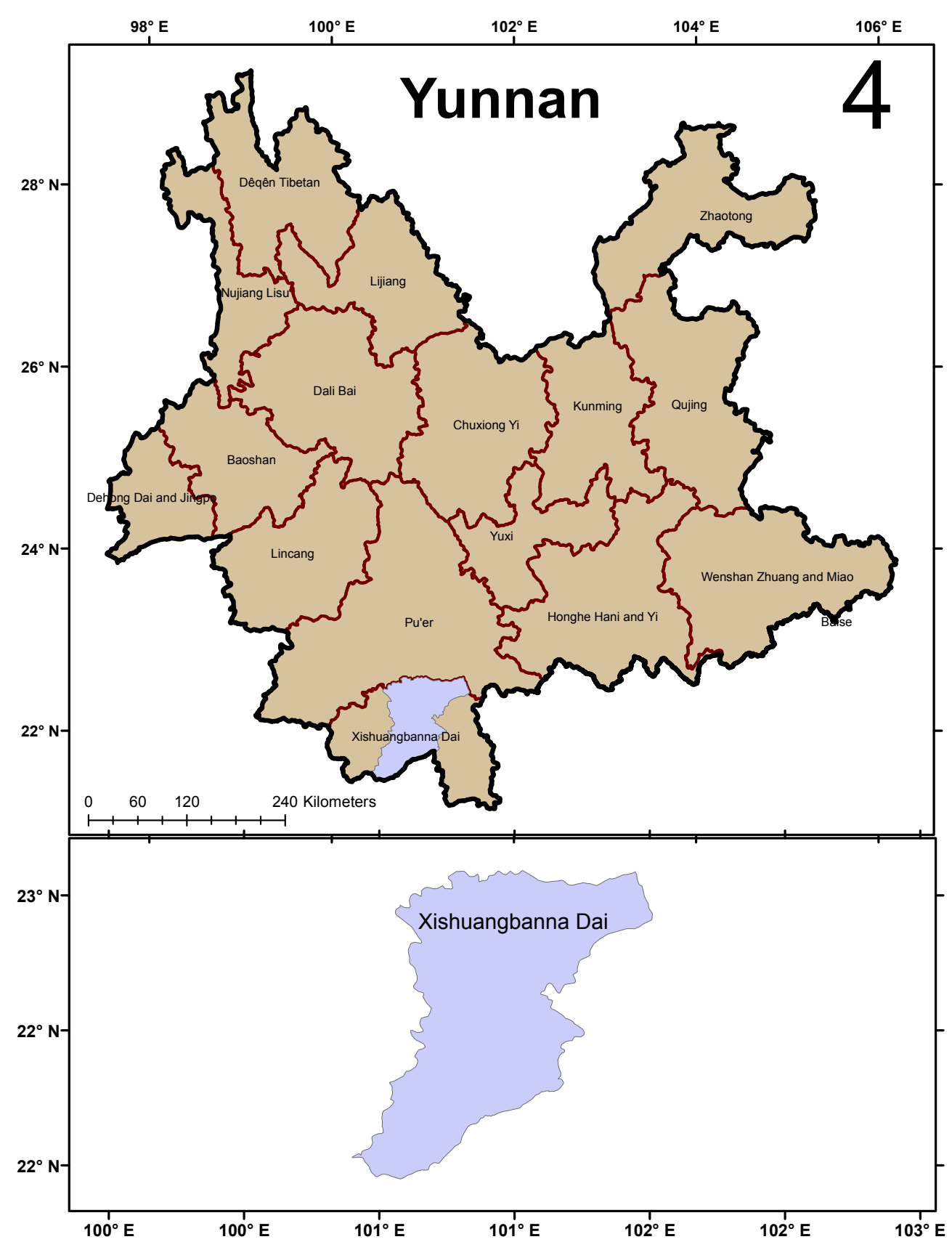

Figure 1. Geographical location of Yunnan Province. The inset map indicated the location of Xishuangbanna Dai This Map was produced on 18th December 2019 by Misiani Zachary. 
Xishuangbanna is a region in the southernmost of Yunnan Province $\left(99^{\circ} 56^{\prime} \sim 101^{\circ} 50^{\prime} \mathrm{E}, 21^{\circ} 08^{\prime} \sim 22^{\circ} 36^{\prime} \mathrm{N}\right)$. It is one of the richest areas of biodiversity in the world. It has over 3500 kinds of higher plants, 700 kinds of higher animals and 1500 kinds of insects. Among the plants, 35 kinds of plants belong to the tertiary period's tropical relict species, and 150 are local species. Moreover, there are 1572 kinds of cash crops (including 782 herbs). Although Xishuangbanna Prefecture only occupies $0.2 \%$ area of China, $25 \%$ of the plant species of China are found in Xishuangbanna [11]. On October $8^{\text {th }} 1993$, Xishuangbanna National Nature Reserve was formally recognized by UNESCO as an International Biosphere Reserve [7].

\section{The Impacts of Rubber Plantation}

\subsection{Loss of Agrobiodiversity}

Based on long-term natural selection and artificial selective breeding, Yunnan is rich in upland rice varieties, which occupy the first place in China. It also contains diverse gene resources [1] In 1981, the cultivation area of upland rice in Yunnan Province was 100 thousand hectares [13]. There were 1100 local varieties of upland rice. Xishuangbanna is one of main regions to plant upland rice. Ethnic minorities in Yunnan have tradition to plant upland rice by shifting agriculture. Along with large scale plantation of rubber trees and other cash trees, however, shifting land area for upland rice has been rapidly decreased. In some villages, villagers completely quit planting upland rice. Many upland rice varieties disappeared. On the one hand, the loss of upland rice varieties poses a threat to the genetic diversity of upland rice which in turn affects selection and breeding of new upland rice varieties. On the other hand, relevant plantation and management technology, traditional ecological knowledge and culture of upland rice are also disappearing gradually [1].

After the last expansion of rubber plantation area in 2005 , agro-biodiversity represented by upland rice quickly disappeared in Manshan Village. According to investigation, there are 5 upland rice varieties planted by villagers in shifting agriculture, which in Bulang language are "Anwai", "Gunbeng", "Anwei", "Kuodao", and "Kao nuopi”.

Based on investigation on two research sites by research team----Manshanshangzhai village and Manshanxiazhai village, we found that since 2005, cultivated varieties of upland rice had quickly decreased, and in 2007 villagers totally gave up upland rice cultivation. Considering that villagers only kept seeds of upland rice for two years, in 2009 upland rice variety in the two villages totally disappeared. Through comparing household numbers who planted upland rice between 2005, 2007 and 2009, we see changes from two aspects Table 1 firstly, upland rice cultivation totally disappeared in 2009; secondly, from the aspect of altitude we see that household numbers from Manshanxiazhai village with low altitude were obviously less than such numbers from Manshanshangzhai village with high altitude, and upland rice cultivation in Manshanxiazhai village disappeared two years earlier than Manshanshangzhai village.

Table 1. Upland Rice Varieties Comparison in 2005, 2007 and 2009 (statistics from 2009, 2010 investigation data).

\begin{tabular}{llllll}
\hline \multirow{2}{*}{ Upland Rice Variety } & \multicolumn{2}{l}{$\begin{array}{l}\text { Household Numbers from Manshanshangzhai village (n=25 } \\
\text { households) }\end{array}$} & $\begin{array}{l}\text { Household Numbers fromManshanxiazhai village } \\
\text { (n=25 households) }\end{array}$ \\
\cline { 2 - 6 } & $\mathbf{2 0 0 5}$ & $\mathbf{2 0 0 7}$ & $\mathbf{2 0 0 9}$ & $\mathbf{2 0 0 5}$ & $\mathbf{2 0 0 7}$ \\
\hline "Anwai" & 12 & 8 & 0 & 11 & 0 \\
"Gunbeng" & 11 & 8 & 0 & 9 & 0 \\
"Anwei" & 13 & 6 & 0 & 9 & 0 \\
"Kuodao" & 15 & 7 & 0 & 7 & 0 \\
"Kao nuopi" & 14 & 5 & 0 & 11 & 0 \\
\hline
\end{tabular}

After 2005 in Manshan village nobody planted upland rice anymore. Today only the elders remember the upland rice variety, while young people seldom know. The last upland rice seeds were kept in 2007, but those seeds cannot be planted, because they already exceed the time limit for storage.

Besides the upland rice, other traditional crop varieties are also gradually disappearing. Large amount of wild and semi-wild editable plants also faces treats from rubber cultivation. By doing questionnaire with villagers, we understand current situation of agrobiodiversity in Manshan Village and factors threatening the biodiversity Table 2.

Table 2. Wild and Semi-Wild Edible Plant Resources Situation and Threatening Factors (data from 2009 and 2010 investigation).

\begin{tabular}{|c|c|c|}
\hline Crop Name & In Bulang Language & Use \\
\hline Broomcorn & Siqi & $\begin{array}{l}\text { 1. to make food, sugar and broom; } \\
\text { 2. its caryopsis can be used for medicine that can eliminate dampness and phlegm; } \\
\text { 3. to make Kaoliang spirit; }\end{array}$ \\
\hline Millet & Lugu & To make food, forage and local wine; \\
\hline Cratevaunilocularis & Hamiao & $\begin{array}{l}\text { Its leaves can be eaten; } \\
\text { To make alcohol; }\end{array}$ \\
\hline Broad-leaf Chives & Guqi & $\begin{array}{l}\text { Its leaves and roots can be eaten, such as cooking chicken, cold and dressed with source, mixed } \\
\text { with chili. }\end{array}$ \\
\hline Elsholtziakachinensis & Pageling & Its stem leaf can be eaten directly, or by frying and cooking. \\
\hline Plantagoasiatica L. & Habakuza & All of it can be eaten. \\
\hline Polygonumhydropiper & Puwei & It stems and leaf can be eaten. \\
\hline
\end{tabular}




\begin{tabular}{lll}
\hline Crop Name & In Bulang Language & Use \\
\hline Eryngiumfoetidum L. & Pajiangwa & Its leaf can be eaten as seasoning. \\
Crowndaisy chrysanthemum & Demakuang & Its leaf can be eaten by frying or cold and dressed with source. \\
Dregeavolubilis & Huolei & Its leaf can be eaten by cooking, frying or roasting. \\
Ficusauriculata & $\mathrm{A} \mathrm{pu}$ & Its leaf and fruit can be eaten by cooking with pook or frying. \\
Pteridiumaquilinum & $\mathrm{A}$ wa & Its leaf can be eaten by frying or roasting. \\
Asiatic centella & Da gong & Its stem and leaf can be eaten in raw, or by cooking soup and frying. \\
Linderaglauca & Xi bi & Its leaf can be eaten directly in raw, and its fruit can be pounded for making seasoning. \\
Fructusamomi & Mei luo & Its bud, fruit and stem can be eaten by roasting or cooking. \\
Tetrastigmaplanicaule & Xiqiaaqie & Its leaf and fruit can be eaten by pickling, pounding, cooking, frying or roasting. \\
Musa wilsonii & A du & Its bud and flower can be eaten by frying or roasting. \\
Solanumtorvum & Mawei & Its fruit can be eaten by frying, roasting or pounding. \\
Bauhinia variegata var. candida & De danla & Its flower and new leaf can be eaten during March and May by frying, roasting or cooking with \\
Spondiashaplophylla & Peiluo & pork. \\
Rhizoma Dioscoreae & Shanyou & It can be pounded to make seasoning. \\
\hline
\end{tabular}

Table 2. Continued.

\begin{tabular}{|c|c|c|}
\hline Crop Name & Situation & Threatening Factors \\
\hline Broomcorn & Its resource is not rich. & $\begin{array}{l}\text { 1. large scale plantation of rubber trees; } \\
\text { 2. Shifting agriculture already disappeared; } \\
\text { 3. impacts from new crop varieties; }\end{array}$ \\
\hline Millet & Its resource is not rich. & $\begin{array}{l}\text { 1. shifting cultivation already disappeared; } \\
\text { 2. large scale plantation of rubber trees; } \\
\text { 1. decrease of forest area; }\end{array}$ \\
\hline Cratevaunilocularis & Its resource is not rich. & $\begin{array}{l}\text { 2. environmental degradation; } \\
\text { 3. only few people plant; }\end{array}$ \\
\hline Broad-leaf Chives & Its resource is rich. & $\begin{array}{l}\text { 1. over collection; } \\
\text { 2. environmental degradation; }\end{array}$ \\
\hline Elsholtziakachinensis & Its resource is rich. & $\begin{array}{l}\text { 1. chemical fertilizer, pesticide and phytocide; } \\
\text { 2. water pollution and environmental degradation; } \\
\text { 3. large sale plantation of rubber trees; } \\
\text { 4. huge decrease of farmland area; }\end{array}$ \\
\hline Plantagoasiatica L. & Its resource is rich. & $\begin{array}{l}\text { 1. chemical fertilizer, pesticide and phytocide; } \\
\text { 2. dam construction and mining; }\end{array}$ \\
\hline Polygonumhydropiper & Its resource is not rich. & $\begin{array}{l}\text { 1. decrease of forest area; } \\
\text { 2. large sale plantation of rubber trees; } \\
\text { 1. chemical fertilizer, pesticide and phytocide }\end{array}$ \\
\hline Eryngiumfoetidum L. & Its resource is not rich. & $\begin{array}{l}\text { 2. decrease of farmland and wetland area; } \\
\text { 3. large scale plantation of cash crops; } \\
\text { 4. environmental degradation; }\end{array}$ \\
\hline Crowndaisy chrysanthemum & Its resource is rich. & $\begin{array}{l}\text { 1. natural disasters such as drought; } \\
\text { 2. chemical fertilizer, pesticide and phytocide; }\end{array}$ \\
\hline Dregeavolubilis & Its resource is rich. & $\begin{array}{l}\text { 1. natural and man-made disasters; } \\
\text { 2. large scale plantation of rubber trees; }\end{array}$ \\
\hline Ficusauriculata & Its resource is not rich. & $\begin{array}{l}\text { 1. decrease of forest area; } \\
\text { 2. large scale plantation of rubber trees; }\end{array}$ \\
\hline Pteridiumaquilinum & Its resource is rich. & $\begin{array}{l}\text { 1. decrease of forest area; } \\
\text { 2. large scale plantation of rubber trees; }\end{array}$ \\
\hline Asiatic centella & Its resource is rich. & chemical fertilizer, pesticide and phytocide \\
\hline Linderaglauca & Its resource is rich. & $\begin{array}{l}\text { 1. decrease of forest area; } \\
\text { 2. large scale plantation of rubber trees; }\end{array}$ \\
\hline Fructusamomi & Its resource is not rich. & $\begin{array}{l}\text { 1. decrease of forest area; } \\
\text { 2. large scale plantation of rubber trees; }\end{array}$ \\
\hline Tetrastigmaplanicaule & $\begin{array}{l}\text { Although its resource is rich, it is decreasing greatly } \\
\text { along with decrease of forest area. }\end{array}$ & $\begin{array}{l}\text { 1. decrease of forest area; } \\
\text { 2. large scale plantation of rubber trees; }\end{array}$ \\
\hline Musa wilsonii & $\begin{array}{l}\text { Although its resource is rich, it is decreasing greatly } \\
\text { along with decrease of forest area. }\end{array}$ & $\begin{array}{l}\text { 1. decrease of forest area; } \\
\text { 2. large scale plantation of rubber trees; } \\
\text { 1. decrease of forest area; }\end{array}$ \\
\hline Solanumtorvum & Its resource is rich. & $\begin{array}{l}\text { 2. large scale plantation of rubber trees; } \\
\text { 3. environmental degradation; }\end{array}$ \\
\hline Bauhinia variegata var. candida & Its resource is not rich. & $\begin{array}{l}\text { 1. decrease of forest area; } \\
\text { 2. large scale plantation of rubber trees; }\end{array}$ \\
\hline Spondiashaplophylla & Its resource is not rich. & $\begin{array}{l}\text { 1. decrease of forest area; } \\
\text { 2. large scale plantation of rubber trees; }\end{array}$ \\
\hline Rhizoma Dioscoreae & Its resource is not rich. & $\begin{array}{l}\text { 1. decrease of forest area; } \\
\text { 2. large scale plantation of rubber trees; }\end{array}$ \\
\hline
\end{tabular}


Based on above analysis, we can see that large-scale plantation of rubber trees directly cause the disappearance of upland rice variety and other wild or semi-wild plant resources. It also causes disappearance of agro-biodiversity and simplification of agricultural landscape.

\subsection{Changes on Local Livelihood}

Relating to shifting agriculture, Bulang people will plant crops on one piece of farmland for one to three years, and then they will abandon it for 7 to 10 years and find new land for cultivation. After 7 or 10 years, when the abandoned farmland is covered by grass and trees, they will burn the vegetation and re-allocate the land. In order to adapt to the shifting agriculture, Bulang people will divide farmland nearby their villages into several pieces, and plant crops on some of them regularly every year [13].

Shifting agriculture was once the main livelihood of Bulang people of Manshan Village. Along with the plantation of rubber trees, however, their livelihood experienced great changes. Firstly, the land utilization type changed. The shifting agriculture required villagers to abandon the farmland in one or three years and reuse it after 7 or 10 years. In order to conserve/continue this tradition, villagers would divide their farmland into many pieces. After the rubber plantation, however, the shifting agriculture in Manshan Village totally disappeared. Secondly, the lunar calendar also changed. Shifting agriculture reflected diversity of land use and crop plantation. During the whole year villagers were busy with cultivation according to lunar calendar. After the rubber plantation, since the land use and crop plantation were simplified, relevant activities according to the lunar calendar were also simplified. Thirdly, agricultural tools were changed. People used special sowing-stick and hoe (see picture as follows) for the shifting agriculture. But now, they use tapping knife and plastic drum for the rubber plantation.

Totally there were 8 shifting farmlands in Manshanxiazhai village that each land had its own name. Among the 8 shifting farmlands, two lands named as Gongjin and Wanggong were fit for cotton plantation. After villagers planted cotton, they would plant upland rice for one season, and then abandon this land for 9 years. During the past, the shifting period was longer from 10 years to 20 years, since land was in abundant supply. In 2007, the shifting agriculture in Manshanxiazhai village totally disappeared, and was replaced by the rubber plantation Table 3.

Table 2. Changes on Land Use in Manshan Village (2009 and 2010 investigation data).

\begin{tabular}{llll}
\hline \multirow{2}{*}{ Altitude } & Shifting agriculture & & Rubber Plantation \\
\cline { 2 - 4 } & Name of Shifting land & Crops & Land Name \\
\hline \multirow{2}{*}{ Between 800 meters and } & Gongjin (land above mountain valley) & Cotton, Anwai, Gunbeng \\
980 meters & Wanggong (land at top of mountain) & Cotton, Anwai, Gunbeng & \\
& Guji (land at top of small mountain & Anwei, Kuodao, Kao nuopi & \\
Between 700 meters and & Lun caca (land like tower) & Anwai, Anwei, Kuodao, Kao nuopi & \multirow{2}{*}{ Rubber Land } \\
800 meters & Gong kadie (excavated land) & Anwai, Anwei, Kuodao & \\
Between 600 meters and trees \\
700 meters & Gongdi (land besides dam) & Gunbeng, Anwei, Kuodao, Kao nuopi & \\
\hline
\end{tabular}

Table 4: Comparison between lunar calendar of the Shifting agriculture and the rubber plantation is as follows:

Table 3. Changes on Lunar Calendar in Manshan Village (2009 and 2010 investigation data).

\begin{tabular}{|c|c|c|c|}
\hline \multicolumn{2}{|c|}{ Lunar Calendar of Shifting agriculture } & \multicolumn{2}{|c|}{ Lunar Calendar of Rubber Plantation } \\
\hline Month & Agricultural Activities & Month & Cutting Rubber \\
\hline January & To select shifting land for cultivation & 25 of March & To start cutting rubber \\
\hline February & To cut down trees on shifting land from bottom to up & & Period for the rubber cutting; its period is 5 \\
\hline March & To burn shifting land and prepare the soil & March to & days. People will cut the rubber for three days \\
\hline May & $\begin{array}{l}\text { To sow seeds on upland and sloping land not exposed to the } \\
\text { sun; }\end{array}$ & November & $\begin{array}{l}\text { and have a rest for } 2 \text { days. Usually they will } \\
\text { cut from } 2 \text { am before dawn till } 7 \mathrm{pm} \text { in the } \\
\text { afternoon. }\end{array}$ \\
\hline June to July & To sow seeds on lowland and sloping land exposed to the sun; & & \\
\hline July to September & $\begin{array}{l}\text { Weeding. To let upland rice in the milk; To keep land } \\
\text { temperature by burning the land center or the land side. }\end{array}$ & $\begin{array}{l}25 \text { of } \\
\text { November }\end{array}$ & Stop cutting the rubber; \\
\hline October to November & Harvest & & \\
\hline
\end{tabular}

It is difficult to find the sowing stick and hoe for the shifting agriculture in Manshanxiazhai village today. But it is easy to find the tapping knife and plastic drum for the rubber plantation.

Besides the shifting agriculture, collection of edible plants is also Bulang people's traditional subsistence. In Manshan Village, women will take responsibility to collect edible plants from forest, and sometimes men will participate in it. During spring and autumn, women with bamboo baskets on their backs will collect all kinds of wild edible plants such as wild fruits, vegetables, potatoes, bamboo shoots and fungus from forest and nearby their farmland. Sometimes they will transplant wild vegetables on the farmland. The collection can be carried out by one or several villagers, or collectively. 
When there is a wedding ceremony or funeral ceremony, all villagers from the village will collect wild plants collectively. There are 30 kinds of wild vegetables collected by villagers from Manshan Village, such as wild potato, Japanese banana flower, basho heart, mushrooms, wild bamboo shoots, bitter bamboo shoots, wild leek, fiddlehead, houttuynia cordata, small age, caraway, and so on. Along with large scale plantation of the rubber trees, however, forest and shifting land area have quickly decreased. As a result, non-timber forest products have also decreased.

Based on above investigation, we see that traditional livelihood in Manshan Village has changed. The shifting agriculture is replaced by the rubber plantation and totally disappeared. Traditional land use, lunar calendar and agricultural tools do not exist anymore, but have been replaced by rubber land, rubber calendar and rubber tools.

\subsection{Changes on Traditional Ecological Knowledge}

The shifting agriculture is not just local subsistence, but also reflects traditional farming culture created by ethnic minorities. The shifting agriculture is one part of traditional ecological knowledge of ethnic minorities. There are three factors to form the shifting agriculture culture, which are headman and monk, farming ceremony and traditional techniques, and ghost and deity belief. For instance, firstly, in Manshan Village every year the headman or monk will select land which is suitable for the shifting agriculture for villagers. While the headman will select land according to date, geomancy and drawing lots, the monk will select land through inviting the village deity/deity to decide which land is fit for the shifting agriculture together. Selecting land by drawing lots is one unique tradition of Bulang people. Secondly, besides the land selection, there are other farming ceremonies and techniques such as cutting trees ceremony, burning land ceremony, sowing ceremony, praying for good harvest ceremony, eating new rice, threshing ceremony and calling grain soul ceremony. Thirdly, Bulang people have 8 ghosts and deities. Specifically, they have the ghost of "Da gui" to dominate production, good fortune and disaster, the ghost of "Tian gui" to dominate wind, rain, thunder and lightning, the ghost of "Lu daogui" to dominate upland rice harvest, the ghost of "Shuigui" to dominate water, the ghost of "Shu gui" to dominate trees, the ghost of "Mianhuagui" to dominate cotton, the ghost of "Di biangui" and "Di gui" to dominate the shifting land. Along with the rubber plantation and disappearance of shifting agriculture, relevant traditional ecological knowledge and culture of the shifting agriculture also disappeared. At the same time, the rubber industry also creates its own culture to replace the shifting agriculture culture. It is made by three factors, namely government policies and market, rubber plantation techniques, and scientific and technical personnel Table 5.

Table 4. Comparison between Shifting agriculture and Rubber Plantation.

\begin{tabular}{lll}
\hline & Factors & Function \\
\hline \multirow{3}{*}{ Shifting agriculture } & headman and monk & To decide scope and place for cultivation \\
& farming ceremony and farming techniques & To decide plantation techniques \\
& ghost and Deity belief & To decide impacts \\
Rubber Industry & government policies and market & To decide scope and place for rubber plantation \\
& rubber plantation techniques & To decide plantation techniques \\
& scientific and technical personnel & To decide impacts \\
\hline
\end{tabular}

Besides the impact on shifting agriculture, the rubber plantation also directly causes the disappearance of Bulang people's other beliefs such as animism and nature worship. In their tradition, Bulang people worship nature and believe that it endows many kinds of ghosts and deities to them, such as Mountain deity, Tree deity, Land deity, Water deity, water ghost and so on. Deities will live in plants and animals. Since the rubber plantation forces villagers to plant rubber trees on higher and higher altitude, it not only causes disappearance of biodiversity, but also the traditional beliefs based on ecological environment.

Because of disappearance of their traditions, Bulang people have to face ecological and social problems. For instance, during the past villagers protected their watershed forest very well, because they believed that there had Forest Deity preventing people from over exploiting the forest. In order to expand the rubber plantation area, however, villagers even cut down trees from the watershed forest, which seriously affects water supply to people and animals. At the same time, there are some villagers giving up the worship to mountain and forest. In order to realize their short-term economic interests, they sign subcontracts with businessmen from outside the village to allow them to plant rubber trees on their farmland, or directly sell their rubber land to them. If we do not stop this activity, there will be more and more villagers losing their farmland in the future.

During our interview, an elder villager told us, "If you do not know Bulang traditional ecological knowledge anymore, you cannot be called Bulang People." Many elder villagers are worried about the disappearance of their traditional ecological knowledge and cultures, since the young generation is not interested in their traditions anymore. The changes on traditional ecological knowledge force Bulang people to replace their traditional farming culture by rubber culture.

\section{Discussion}

However, from our point of view we think that rubber cultivation poses not only an ecological problem, but poses a problem for traditional ecological knowledge and cultural diversity as well. To villagers living in Southeast Asian region (including Xishuangbanna), the traditional ecological knowledge is a comprehensive system, which not only includes natural resource management and genetic resource 
protection, but also recognition of ethnical identities and heritage of biological and cultural diversity. The traditional ecological knowledge not only protects biodiversity, but also enriches cultural diversity of ethnic minorities.

Through the case study of Manshan Village, we see that policy-led large-scale development of the rubber industry in Xishuangbanna not only causes the quick disappearance of biodiversity, but also leads to the break off of the traditional ecological knowledge of ethnic minorities, and finally causes simplification and disappearance of cultural diversity. As mentioned by one villager, "although we still can find or buy upland rice seeds from Burma and plant on our farmland, we could not recover our Bulang traditional ecological knowledge and culture from Burma, if it would disappear in the future." To some extent, the protection of traditional ecological knowledge and cultural diversity is more important and urgent than the biodiversity conservation.

\section{Conclusion}

Based on this investigation report, we hope that policy decision makers will consider both economic development and ecological protection and cultural heritage in policy making, which can further strengthen ethnic minorities' ecological protection and cultural heritage preservation in the future.

\section{Acknowledgements}

Special thanks goes to Sichuan Provincial Key Research Base of Philosophy and Social Sciences, Yi Cultural Research Center, "Research on the Legal Mechanism of the Religion and the Conservation of Biodiversity in the Yi Nationality Area" (YZWH1714); Project of Leshan Normal University, "Legislative Research on the Conservation of Biodiversity in Ethnic Areas" (WZD049) and "Comparative Research on the Law Norms of Biodiversity Conservation in Ethnic Areas" (XJR18010) for the support. Misiani is also thankful to the Kenya Meteorological Department for which assisted him with its resources while pursuing this research. The anonymous referees are kindly acknowledged for their constructive reviews and helpful suggestions.

\section{References}

[1] Gong ZL, Guo HJ. 2004. Xishuangbanna community upland rice variety diversity and in situ conservation [in Chinese with English abstract]. Biodiversity Science 12 (4): 427-434.

[2] Hongmei Li, T. Mitchell Aide, Youxin Ma, Wenjun Liu, Min Cao. 2007. Demand for rubber is causing the loss of high diversity rain forest in SW China. Biodivers Conserv 16: 1731-1745. https://doi.org/10.1007/s10531-006-9052-7

[3] Houghton, R. A. 1994. The worldwide extent of land-use change. BioScience 44: 305-313. https://doi.org/10.2307/1312380

[4] Lambin, E. F., B. L. Turner II, H. J. Geist, S. Agbola, A. Angelsen, J. W. Bruce, O. Coomes, R. Dirzo, G. Fisher, C. Folke, P. S. George, K. Homewood, J. Imbernon, R. Leemans,
X. Li, E. F. Moran, M. Mortimore, P. S. Ramakrishan, J. F. Richards, H. Skanes, W. Steffen, G. D. Stone, U. Svedin, T. Veldkamp, C. Vogel, and J. Xu. 2001. The causes of land-use and land cover change: Moving beyond the myths. Global Environmental Change 11: 261-269. https://doi.org/10.1016/S0959-3780(01)00007-3

[5] Pei SJ. 1991. Managing for biological diversity conservation in temple yards and holy hills: The traditional practices of the Xishuangbanna Dai Community in southwest China. In: Hamilton LS, editor. Ethics, Religion and Biodiversity. Cambridge, United Kingdom: White Horse Press, pp 118-132.

[6] Sala, O. E., F. S. Chapin, III, J. J. Armesto, E. Berlow, E. J. Bloomfield, R. Dirzo, E. Huber-Sanwald, L. F. Huenneke, R. B Jackson, A. Kinzig, R. Leemans, D. M. Lodge, H. A. Mooney, M. Osterheld, N. L. Poff, M. T. Sykes, B. H. Walker, M. Walker, and D. H. Wall. 2000. Biodiversity: Global biodiversity scenarios for the year 2100. Science 287: 1770-1774. https://doi.org/10.1126/science.287.5459.1770

[7] UNESCO, 2007. The Man and Biosphere Programme, available online at http://www.unesco.org/mabdb/br/brdir/directory/biores.asp.co $\mathrm{de}=\mathrm{CPR}+10 \&$ mode $=$ allVitousek, P. M., H. A. Mooney, J. Lubchenco, and J. M. Melillo. 1997. Human domination of earths ecosystems. Science 277: 494-499. https://doi.org/10.1126/science.277.5325.494

[8] Wang YH, Xu T. 1998. Analysis and evaluation of Xishuangbanna rubber plantation [in Chinese]. Journal of Yunnan University 20: 605-608.

[9] Xu JC. 2006. The Political, Social, and Ecological Transformation of a Landscape the Case of Rubber in Xishuangbanna, China. Mountain Research and Development $\begin{array}{lllll}\text { Vol } & 26 & \text { No } & 3 \text { : } & 254-262\end{array}$ https://doi.org/10.1659/0276-4741(2006)26 [254: TPSAET]2.0.CO;2.

[10] Xu JC. 2002. Hani practices of intensification of shifting cultivation in Xishuangbanna, Southwest China: Rattan and tea based fallow management. In: Cairns MF, editor. Indigenous Strategies for Intensification of Shifting Cultivation in Asia-Pacific. Proceedings of a Regional Conference Held in Bogor, Indonesia on June 23-27, 1997. Chiang Mai, Thailand: International Centre for Research in Agroforestry.

[11] Xu JC, Fox J, Zhang PF, Fu YS, Yang LX, Qian J, Leisz S, Vogler J. 2005. Land-use and land-cover change and farmer vulnerability in Xishuangbanna Prefecture in southwestern China. Environmental Management 36 (3): 404-413. https://doi.org/10.1007/s00267-003-0289-6

[12] Yang WM, Qin W. 2009. Yunnan Xishuangbanna rubber development on ecological environment impact assessment [in Chinese with English abstract]. Ecological Economy 01: 336-339.

[13] Yin ST. 2008. Away in the hill fire - Anthropological Perspective on Shifting agriculture [in Chinese], China: Yunnan people's Publishing House.

[14] Zhang MQ, Zhou KX, Xue DY. 2007. Rubber's Influence on Tropical Rainforest in Xishuangbanna and How to Reduce the Impact [in Chinese with English abstract]. Ecological Economics 02: 377-378.

[15] Zhou JW. 1982. History and current status of Yunnan upland rice production [in Chinese]. Yunnan agricultural science and technology 05: 22-26. 